\title{
Применение препарата протромбиного комплекса Октаплекс при различных кровотечениях у больных с дефицитом фактора $\mathrm{X}$
}

\author{
Э.А.Кадымова ${ }^{1}$, Н.Я.Юсифова ${ }^{1}$, Г.А.Ализаде ${ }^{1}$, Г.М. Эфендиева ${ }^{1}$ \\ 1 Азербайджанский Государственный Институт усовершенствования врачей им. А.Алиева, кафедра \\ гематологии и акушерства гинекологии
}

\begin{abstract}
Актуальность адекватного лечения различных кровотечений у больных с коагулопатиями обусловлено широким распространением этого состояния при дефицитах различных факторов сворачиваемости крови. Целью кастоящего исследования было изучения результатов применения препарата протромбинового комплекса Октаплекс у больных с дефицитом X фактора и у больных с приобретенной формой гемофилии. Материалы и методы исследования Под нашим наблюдением было 27 больных дефицитом фактора Х. Все больные с различными формами кровотечения находились на стационорном лечении и диспансерном наблюдении в Республиканском центре гемофилии гор. Баку Азербайджанской Республики. Исследование имело ретроспективный характер. Для оценки гемостаза были использованы следующие параметры лабораторных исследований: активность факторов крови VIII, VII, Хи др, АЧТВ, ПИ, ПВ, ИНР, время кровотечения по Li Uayt, фибриноген.
\end{abstract}

Ключевые слова: лечения, Октаплекс, фактор X

Введение. Физиологический фактор Х является самым важным активатором протромбина, присутствие его в протромбиновомкомплексе ускоряет превращение протромбина в тромбин. Тяжелый дефицит фактора $\mathrm{X}$ характерен для гомозигот и наследуется как аутосомный рецессивный признак с частотой 1:1.000.000 в популяции (Н.Н. Мамаева, С.И.Рябов 2008). Гетерозиготы с аномалией фактора $\mathrm{X}$ встречаются значительно чаще и обычно не имеют проявлений кровоточивости. $(1,3,11)$ Пациенты с тяжелым дефицитом фактора $\mathrm{X}$ (менее 1\%) в отличие от больных с другими формами редких коагулопатии имеют нашболеетяжелые проявления кровоточивости, начиная с периода новорожденности. Нашболее частыми проявлениями этого заболевания являются кровотечения из слизистых оболочек (носовые, десневые и др). Менноррагии отмечаются у половины женщин репродуктивного возраста. У пациентов с умеренным дефицитов факторов X (от 1\% до $5 \%)$ кровотечения обычно возникают в связи с травмами или во время оперативных вмешательств. Напротив, люди с уровнем фактора X выше 6\% особенных жалоб на кровоточивость не предъявляют, за исключением легкой склонности к возникновению поверхностных синяков, и выявляются обычно случайно при обычном лабораторном обследовании или при обследовании членов семьи больного страдающего кровоточивостью. Дефицит фактора $\mathrm{X}$ позволяет заподозрить одновременно выявленное у больного удлинениепротромбиного времени и АЧТВ на фоне нормальной концентрации фибриногена. Окончательный диагноз может быт поставлен только на основании определения активности $\mathrm{X}$ фактора $(3,5,6)$.

Лечение пациентов с врожденным дефицитом фактора $\mathrm{X}$ осуществляется ингибиторами фибринолиза (транексамовая кислота), свежезамороженной плазмой (СЗП), в некоторых случаях даже при минимальном количестве фактора $\mathrm{X}$ гемостатический эффект оказывает рекомбинатный фактор VII. Препарат Октаплекс представляет достаточно новый, пока редко применяемый подход для остановки кровотечения у больных с 
дефицитом $\mathrm{X}$ фактора и пациентов с ингибиторным осложнением. Вместе с тем по результатам данного исследования он оказывается эффективным во всех указанных случаях применения.Уровень фактора $\mathrm{X}$ в пределах от $10 \%$ до $20 \%$ считается достаточным для достижения гемостаза даже в послеоперационном периоде. Поскольку период полужизни введенного фактора $\mathrm{X}$ составляет 60 часов, ежедневных трансфузий препаратов заместительного действия не требуется. Самое главное, чтобы уровень фактора X не снижался менее 10\%. Надо помнить, что следует избегать одновременного использования антифибринолитических средств и препаратов протромбинового комплекса. Последние, во избежание тромботических осложнений, нужно использовать с осторожностью у пациентов с заболеванием печени, большими гематомами и травмами, у новорожденных и при дефиците антитромбина. Во время беременности уровень фактора $\mathrm{X}$ повышается, что может обеспечить благополучие в послеродовом периоде у женщин с его умеренным дефицитом. Назначение препаратов, содержащих фактор X, рекомендуется вводить сразу после родов женщинам с его тяжелым дефицитом, но с большой осторождостью (контроль лабораторных данных) из-за возможного развития тромботических осложнений. Пациенты с уровнем фактора X выше $10 \%$, не имеющие симптомы выраженной кровоточивости, обычно не нуждаются в заместительной терапии, за исключением ситуации, связанных, с проведением обширных хирургических вмешателыств.

При обследовании пациентов необходимо учитывать активность фактора Х. Клинические проявления болезни весьма разнообразны и могут меняться на протяжении жизни.

Таблица 1. Распределение пациентов с дефицитом X фактора по возрасту и полу.
$\Pi-27$

\begin{tabular}{|l|c|}
\hline Женщины & 7 \\
\hline Мужчины & 20 \\
\hline Пациенты до 16 лет & 10 \\
\hline Пациенты выше 16 лет & 17 \\
\hline
\end{tabular}

Как видно из таблицы обследованные больные были в основном мужского пола (п-20) и взрослые (п-17)

Таблица 2. Распределение пациентов с дефицитом X фактора по степени тяжести.

\begin{tabular}{|c|c|c|}
\hline \multicolumn{3}{|c|}{ Активность X фактора } \\
\hline $0-1 \%$ & $1-5 \%$ & выше $5 \%$ \\
\hline 22 & 3 & 2 \\
\hline
\end{tabular}

Как видно из таблицы 2, обследованные больные в основном были с тяжелым дефицитом X фактора (п-22), активность фактора Х было менее $1 \%$.

Таблица 3. Распределениебольных с дефицитом $\mathrm{X}$ фактора по видам кровоточивости.

\begin{tabular}{|l|c|}
\hline Носовые & 8 \\
\hline Десневые & 6 \\
\hline Желудочно-кишечные & 3 \\
\hline $\begin{array}{l}\text { Экстракция зубов и др. хирургические } \\
\text { вмешательства }\end{array}$ & 8 \\
\hline Маточные & 2 \\
\hline п & 27 \\
\hline
\end{tabular}

Для обеспечения гемостаза всем выше указанным пациентам вводилось только препарат Октаплекс, который содержит факторы свертывания крови II, IX, VII и X, которые синтезируются в печени с помощью витамина К, чаще называются неактивированнымпротромбиновым комплексом.

Введение этого препарата может быстро корригировать нарушения коагуляции у пациентов с дефицитом одного или нескольких этих факторов.

Таблица 4. Пределы периода полувыведения из плазмы крови: 


\begin{tabular}{|l|l|}
\hline $\begin{array}{l}\text { Фактора } \\
\text { свертывания }\end{array}$ & Период полувыведения \\
\hline Фактор II & $48-60$ ч \\
\hline ФакторVII & $1,5-6$ ч \\
\hline Фактор IX & $20-24$ ч \\
\hline Фактор X & $24-48$ часов \\
\hline
\end{tabular}

Таблица 5. Доза и длительность назначения препарата Октаплекс в зависимости от формы кровотечения.

\begin{tabular}{|c|c|c|}
\hline $\begin{array}{c}\text { Формы } \\
\text { кровотечения }\end{array}$ & $\begin{array}{c}\text { Приблизительная } \\
\text { доза (мл } \\
\text { Октаплекс/кг } \\
\text { массы тела) } \\
\end{array}$ & Колво дней \\
\hline Носовые & $0,9-1,3$ & 3 дня \\
\hline Десневые & $0,9-1,3$ & 3-5 дней \\
\hline $\begin{array}{l}\text { Желудочно } \\
\text { кишечные }\end{array}$ & $1,6-1,9$ & $\begin{array}{c}\text { До } \\
\text { стабилизаци } \\
\text { и состояния } \\
\text { гемостаза } \\
\end{array}$ \\
\hline $\begin{array}{l}\text { Хирургические } \\
\text { вмешательства }\end{array}$ & $>1,9$ & $\begin{array}{c}5 \text { дней } \\
\text { ежедневно } \\
\text { потом ч/д } \\
\end{array}$ \\
\hline Маточные & $1,6-1,9$ & $\begin{array}{c}\text { до } \\
\text { стабилизаци } \\
\text { и гемостаза }\end{array}$ \\
\hline
\end{tabular}

Примечание: Разовая доза не должная превышеть 3000 ME (120 мл Октаплекса). Всем пациентам вводилось только Октаплекс в индивидуальной дозе в/в однократно в день и в динамике с лабораторным контролем. Гемостаз обеспечивалось полностью.

Доза и длительность заместительной терапии зависит от тяжести нарушения локализации и степени кровотечения и клинического состояния.

Количество и частоту введения следует вычислять индивидуально для каждого пациента. Интервалы между введениями доз должны быть адаптированы разностью полужизни факторов свертывания крови в составе Октаплекса. Необходимые индивидуальные дозы можно определить только на основании регулярного определения активности X фактора или общего определения уровней протомбинового комплекса (INRмеждународныйкоффициент нормализации МHO-Междуродное нормализованное отношение/InternationalNormalizedRatio-INR)- стандартизированнаяснетема

измерения протромбированного времени.Мы также применялипрепарат Октаплекс у больных с дефицитом фактора VII и у 3-х больных с приобретенной формой гемофилии, получили хороший гемостатический эффект, о котором сообщим в следующих публикациях.Применение препарата Октаплекс представляет достаточный новый, пока еще не везде применяемый, но перспективный терапевтический подход для остановки кровотечений $\mathrm{y}$ пациентов $\mathrm{c}$ дефицитом $\mathrm{X}$ фактора свертывания. В частности, указанный препарат оказался эффективным во всех случаях применения.

Таким образом лечение больных с дефицитом фактора $\mathrm{X}$ целесообразно проводить с протромбиновым комплексом препаратом Октаплекс. т.к. обеспечивает быстрый и стойкий терапевтический эффект в сравненим с лечением других имевшихси препаратов (СЗП, транексамовая кислота и др).

Финансовый источник: При написании статьи не использовались финансовые ресурсы.

Конфликт интересов: Нет.

\section{СПИСОК ЛИТЕРАТУРЫ}

1. Зубаиров Д.М. Молекулярные основы свертывания крови и тромбообразования. Казань, 2000, 364 с.

2. Н.Н. Мамаева, С.И.Рябов, Гематология ,2008, $543 \mathrm{c}$.

3. Мамот А.П. Патология гемостаза принципы и алгоритмы клинико-лабораторной диагностики.СПБ. формат Т. 2006, 208 с.

4. Мамаев А.Н. Коагулопатии: руководство, Москва, 2012, 264 с.

5. Руководство по гематологии в 3 I. под.ред. А.И. Воробьева. Москва, 2005.

6. Рукавицын О.А. Гематология Москва,2015, $770 \mathrm{c}$.

7. Ellis Neufeld Current risks limitations of living with severe haemophiliaA.Symposium 10 th Annual Congress of EAHAD, 2017.

8. Giralami A, Scarparo R, Allemand E. Congenitae factorX deficiencies with a defect only or predominantly in the axtrinsic or in the intrinsic system: a critical evaluation. Am Y 
Haemotol.2008, 83:668-71.

9. Textbook of Hemophilia Christine Lee, Erik Berntop, Keith Hoots, 464 p.

10. Tai S, Herzog RW, Margaritis P. et.al. Aviable mouse model of factor $\mathrm{X}$ deficiency provides evidence for maternal transfer of factor $\mathrm{X}$. J ThrombHaemost 2008, 6:339-45

11. Todd T, Perry D, Hayman E, Lawrence K, Gattens M, Baglin T. Severe factor X deficiency due to a homozygous mutation (Cys 364 Arg) that discrupts a disulphide bond in the catalytic domain. Haemophilia 2006, 12:621-4. 